\title{
MATERIAIS E MÉTODOS DE CONTROLE DO BIOFILME EM PRÓTESES REMOVÍVEIS - REVISÃO DE LITERATURA
}

\author{
MATERIALS AND BIOFILM CONTROL METHODS FOR \\ REMOVABLE DENTURES - LITERATURE REVIEW
}

\author{
Ludmila Dias Carvalho*, Larissa Dominguez Pereira Dantas**, Emilena Maria Castor Xisto \\ Lima***
}

\author{
Autora para correspondência: Ludmila Dias Carvalho - ludycdl@gmail.com \\ * Mestrado em andamento na Escola Bahiana de Medicina e Saúde Pública \\ **Especialista em Prótese Dentária pela Escola Bahiana de Medicina e Saúde Pública \\ ***Professora adjunta da Faculdade de Odontologia da Universidade Federal da Bahia e da Escola Bahiana \\ de Medicina e Saúde Pública
}

RES U M O

\begin{abstract}
A atuação do dentista é decisiva tanto no tratamento reabilitador bem como na instrução e motivação do paciente quanto à higienização das próteses no momento de sua instalação e durante todo o seu uso. Cabe ao cirurgião-dentista conhecer os materiais e métodos empregados na manutenção da higiene bucal, selecioná-los e, de acordo com as peculiaridades de cada caso, motivar e orientar sua aplicação. Entretanto, o que se observa é uma dificuldade dos profissionais em utilizar um protocolo de controle de biofilme na reabilitação bucal com próteses removíveis. O objetivo deste trabalho foi revisar a literatura acerca dos materiais e métodos disponíveis para a correta higiene das próteses removíveis.
\end{abstract}

PALAVRAS-CHAVE: reabilitação bucal; próteses removíveis; biofilme.

\section{A B S T R A C T}

The role of the dentist is crucial both in rehabilitation treatment as well as in education and motivation of the patient regarding the hygiene of the prosthesis at the time of installation and throughout its use. It is important for the dentist to know the materials and methods used in maintaining oral hygiene, select them and motivate and guide their implementation according to the peculiarities of each case. However, it has been observed a difficulty of professionals to use a biofilm control protocol in oral rehabilitation with removable dentures. The objective of this study was to review the literature about the materials and methods available for the proper care of dentures.

KEYWORDS: Oral rehabilitation, Removable dentures, Biofilm. 


\section{INTRODUÇÃO}

Um dos requisitos básicos de uma reabilitação bucal bem sucedida é sua longevidade que está diretamente relacionada com a qualidade do trabalho do profissional e com a manutenção da saúde bucal por parte do paciente. Na reabilitação bucal, o dentista devolve ao paciente a estética dental e facial, a função mastigatória e a melhora na sua autoestima, porém, um bom planejamento por si só, não leva uma prótese ao sucesso nem aumenta sua longevidade, sendo necessária orientação do profissional ao usuário das próteses em relação aos materiais e métodos de higienização bucal e das próteses ${ }^{1}$.

Existe uma forte evidência de que as próteses dentais funcionam como verdadeiros reservatórios para microrganismos patogênicos e oportunistas ${ }^{2} \mathrm{e}$ sabe-se que o controle de biofilme é essencial para limitar a produção de agentes irritantes locais que levam à inflamação e destruição periodontal nos usuários de próteses parciais ${ }^{3}$.

O biofilme que se adere na superfície das próteses tem estrutura similar àquele que se acumula na superfície dos dentes naturais. Uma das diferenças consiste na grande quantidade da espécie Candida que acomete grande parte dos usuários de próteses totais, podendo vir a causar as estomatites protéticas ${ }^{4,5}$.

Por isso, os pacientes devem ser instruídos sobre os cuidados de higiene e manutenção de suas próteses removíveis e é imprescindível não somente a higiene diária dessas próteses bem como dos tecidos moles e dentes naturais remanescentes a fim de manter a saúde da mucosa e das estruturas periodontais de suporte (6).

Existe uma variedade de métodos de higienização disponíveis para limpeza das próteses, mas o que se observa é uma dificuldade do profissional em indicar um protocolo de controle de biofilme na reabilitação bucal, além da negligência por parte do dentista em buscar e repassar essas informações ao paciente e do próprio paciente em não realizar.

Muitos estudos comprovam que os pacientes recebem pouca ou nenhuma informação quanto à higiene de suas próteses ou, muitas vezes, quando a recebem, estas informações são incompletas ou incorretas $7,8,9,10$.

Desse modo, a atuação do profissional é decisiva tanto no tratamento protético propriamente dito bem como na instrução e motivação do paciente quanto aos seus deveres e cuidados em relação à sua prótese. Cabe ao profissional conhecer os materiais e métodos empregados na manutenção da higiene bucal, selecioná-los e, de acordo com as peculiaridades de cada caso, motivar e orientar sua aplicação, para que os cuidados sejam efetivos na conservação do estado de saúde obtido com o tratamento $^{11,12}$.

As próteses removíveis podem ser higienizadas, a depender do modo de ação, de forma mecânica, cujo método mais comum é a escovação com água e sabão neutro ou dentifrícios; de forma química, onde as próteses são imersas em alguma solução química, ou ainda com associação de ambos os métodos ${ }^{13}$.

Assim, o objetivo desse trabalho foi revisar a literatura acerca dos materiais e métodos disponíveis para a correta higiene das próteses removíveis.

\section{REVISÃO DE LITERATURA}

\section{Métodos mecânicos}

\section{Escovação}

O método mecânico mais utilizado é a escovação que tem a vantagem de ser um método simples, de baixo custo e efetivo na remoção de manchas e depósitos orgânicos, porém, oferece dificuldades para pacientes com problemas motores, além de existir a possibilidade de desgaste da resina acrílica e danos a materiais reembasadores ${ }^{14}$.

A indicação de uma escova adequada é importante para se conseguir um melhor alcance de todas as áreas da prótese (interna e externa), evitar possíveis acidentes que podem ser causados por uma escova que não se adapte às superfícies das próteses e utilizar cerdas que não provoquem 
ranhuras nas superfícies polidas das peças, o que a deixa mais propensa à retenção do biofilme e resíduos alimentares ${ }^{15}$.

A escova específica para higiene de próteses removíveis possui cerdas macias, com tufos dos dois lados da cabeça sendo um mais grosso para a parte externa e um mais comprido para alcançar a parte mais profunda da região basal. Entretanto, a escova para dentes naturais ainda é a mais utilizada ${ }^{6,9}$.

Reeson et al., sugeriram uma escova modificada para pacientes com problemas motores. A escova seria anexada na pia através de um sistema de sucção na sua base permitindo ao paciente segurar apenas a prótese enquanto realiza o movimento de escovação ${ }^{16}$.

O período de higienização também é importante, uma vez que o biofilme se deposita nas próteses de forma similar àquela dos dentes naturais ${ }^{4}$. 0 mais indicado então é a escovação três vezes ao dia ou após a alimentação, da mesma forma que nos dentes naturais. Além disso, deve-se instruir o paciente a trocar as próteses pelo menos a cada 5 anos, pois quanto maior o tempo de uso, maior a degradação da resina, causando porosidades e favorecendo o acúmulo de depósitos orgânicos que, posteriormente, desencadeará lesões aos tecidos de suporte ${ }^{17}$.

O ideal é que a escova utilizada tenha cerdas macias e, caso se utilize algum dentifrício como complementar na higienização, que este seja não abrasivo. Entretanto, a dificuldade de se encontrar escovas com cerdas específicas, além de dentifrícios específicos não abrasivos para higienização de próteses removíveis, limita a eficácia desse método de higienização ${ }^{18,19}$.

Vários estudos confirmaram que o método mecânico de escovação é o mais popular e que somente uma parte da população utiliza algum método químico como auxiliar de limpeza $a^{4,11,20}$.

\section{Micro-ondas}

O método mecânico de desinfecção por micro-ondas consiste em imergir a prótese em água e expor 0 conjunto às micro-ondas sendo que 6 minutos com uma potência de $650 \mathrm{~W}$ é o recomendado, porém, seu uso ainda é restrito ${ }^{21}$. Esse método pode ser utilizado nas próteses temporárias sem grampo ou nas próteses totais ${ }^{20,22}$.

Silva, verificou que a irradiação por micro-ondas a $650 \mathrm{~W}$ por 6 minutos foi efetiva para desinfecção de próteses totais contaminadas com Pseudomonas aeruginosa e Bacillus subtilis, além de promover a esterilização daquelas inoculadas com Candida albicans e Staphylococcus aureus. Com relação à estabilidade dimensional de resinas para base de prótese, Silva, afirmou que a esterilização por microondas apresenta influência clínica insignificante nesse processo ${ }^{23}$.

Ribeiro et al, expuseram próteses totais, imersas em água, à irradiação por micro-ondas durante 3 minutos em uma potência de $650 \mathrm{~W}$ que resultou em esterilização das peças e no tempo de 2 minutos observou-se a desinfecção das mesmas. Nesse estudo, não foram avaliados possíveis danos à resina acrílica ${ }^{24}$.

No entanto, Sartori et al, avaliaram o efeito do método de desinfecção química com imersão das peças em solução clorada e desinfecção por microondas na adaptação interna de bases de próteses totais e verificaram que as bases submetidas à desinfecção por este método tiveram aumento gradual de desadaptação, enquanto que as bases imersas em solução clorada não diferiram do grupo controle (sem desinfecção) ${ }^{25}$.

Hussen et al, em 2008, também encontraram resultados semelhantes. Nesse estudo, os autores concluíram que houve uma alteração dimensional significativa da resina acrílica na desinfecção por irradiação a micro-ondas por 6 minutos em potência de $650 \mathrm{~W}$, enquanto que na desinfecção por substância química não houve tal alteração dimensional ${ }^{26}$.

Apesar da desinfecção das próteses pela irradiação de micro-ondas ser um processo de fácil utilização, ser um procedimento rápido e de baixo custo ${ }^{26}$, ainda há controvérsias quanto ao real efeito dessa irradiação na estabilidade dimensional da resina acrílica sofrendo resistência ao seu uso ${ }^{20}$. 
Ultrassom

Outro método mecânico é a utilização do ultrassom (aparelho que converte energia elétrica em mecânica) por parte do profissional ${ }^{4,22}$.

Apesar de remover cálculo e algumas manchas e de não causar danos à estrutura das próteses, este método não é eficiente na remoção do biofilme, pois a agitação ultrassônica por si só não causa redução significativa do número de microorganismos ${ }^{27}$.

Mesmo com o desenvolvimento de pesquisas utilizando $\circ$ aparelho de ultrassom como agente de limpeza de próteses totais, sua eficácia ainda é contraditória, pois não se sabe se sua efetividade é atribuída propriamente à ação mecânica do aparelho ou à solução química que pode ser usada concomitantemente ${ }^{27}$.

Em estudo de Abelson, em 1981, ficou comprovado, numa comparação entre a utilização do aparelho de ultrassom e o uso do peróxido alcalino na higienização de próteses removíveis, que a remoção do biofilme da superfície das próteses analisadas foi muito superior no uso do método mecânico com ultrassom do que com 0 método químico com 0 peróxido alcalino.

Esse método é menos utilizado, pois depende de um maior custo em países em desenvolvimento e maior informação profissional para seu uso, sendo mais recomendado em instituições com pacientes portadores de próteses removíveis, como casas de repouso e hospitais ${ }^{14}$, para $\circ$ consultório odontológico e para pacientes com dificuldades visual e/ou motora ${ }^{22}$.

\section{Métodos químicos}

O uso de substância química para higienização das próteses removíveis já é estabelecido na literatura. Esse método reduz a quantidade de microrganismos na superfície dessas próteses ajudando no seu controle e eliminação, na diminuição da inflamação da mucosa e da estomatite protética ${ }^{3}$.

O agente de limpeza ideal deve remover depósitos orgânicos e inorgânicos das superfícies polidas e especialmente das rugosas, ter ação bactericida e fungicida, ser compatível com o material da prótese, ser de fácil uso e baixo custo ${ }^{13,22,28}$. É tido como vantajoso por englobar todas as áreas da prótese e não causar danos ao aparelho protético, no que se refere à abrasão, sendo um procedimento simples ${ }^{27}$.

Porém, como desvantagens principais, podem ser citadas o clareamento da resina acrílica, a corrosão dos componentes metálicos e $\circ$ alto custo dos produtos no mercado nacional ${ }^{29}$.

No Brasil, além do alto custo, poucos materiais são colocados à disposição dos pacientes ${ }^{30}$, o que se torna um fator dificultador da utilização e propagação dos métodos químicos de higienização de próteses.

O método químico consiste na imersão ou embebição das peças protéticas em substância higienizadora por um tempo determinado por cada fabricante e podem ser divididos em 5 grupos a depender do seu constituinte químico e mecanismo de ação: peróxidos, hipocloritos, ácidos diluídos, desinfetantes e enzimas ${ }^{3}$. Este método tem sido preferido por pacientes deficientes e geriátricos que não conseguem escovar adequadamente suas próteses $^{31}$.

\section{Peróxidos alcalinos}

Os peróxidos alcalinos são os agentes químicos mais utilizados e estão disponíveis em forma de pós ou pastilhas que são dissolvidos em água, podendo ser utilizados em próteses totais e parciais removíveis sem distinção ${ }^{32}$. Removem algumas manchas e depósitos leves, mas são menos efetivos na remoção de cálculos e manchas pesadas, ou seja, seu uso principal está indicado em próteses que são higienizadas frequentemente e que não acumularam depósitos pesados e firmemente aderidos ${ }^{6,29}$.

As peças protéticas são imersas dentro de um recipiente com água e o pó ou pastilha durante alguns minutos ou por toda a noite, a depender das instruções do fabricante, mas geralmente necessitam de bastante tempo em contato com as peças para serem efetivos ${ }^{33}$. Observou-se que 0 uso do peróxido por apenas 15 minutos não foi eficiente para remoção do biofilme ${ }^{34}$, o que vai de encontro ao recomendado e encontrado em algumas 
embalagens dos peróxidos.

No entanto, se o peróxido for usado por um tempo prolongado pode causar clareamento do acrílico $^{33,35}$. Além disso, como desvantagens podem causar edema local, inflamação e descamação da mucosa se as próteses não forem enxaguadas abundantemente após o uso do produto ${ }^{2,29}$.

\section{Hipocloritos}

Os hipocloritos são substâncias também muito utilizadas na higiene das próteses removíveis e muito úteis. São bactericidas e fungicidas e se mostram mais eficazes contra esporos e vírus, pois penetram até $3 \mathrm{~mm}$ na resina acrílica ${ }^{6}$. Removem manchas facilmente, dissolvem alguns componentes salivares e outras substâncias orgânicas, porém não removem cálculo instalado, apenas inibem sua formação ${ }^{27,32}$.

É recomendado que a prótese seja imersa numa solução de $15 \mathrm{ml}$ de hipoclorito de sódio a $2 \%$ ou $3 \%$ (água sanitária) diluídos em $300 \mathrm{ml}$ de água durante, no máximo, 15 a 20 minutos diários. Em seguida, as próteses devem ser imersas em água fria e lavadas de forma abundante a fim de tirar o odor e gosto desagradáveis que o hipoclorito proporciona ${ }^{6}$.

Catão et al, compararam três substâncias químicas (hipoclorito de sódio a 2,25\%, perborato de sódio e clorexidina a $2 \%$ ) empregadas na higienização de 93 próteses totais e constataram que o hipoclorito apresentou melhores resultados na remoção do biofilme, seguido do perborato, sendo que a clorexidina não se mostrou eficiente. Entretanto, nenhum dos métodos químicos isolados conseguiu eliminar todo o biofilme da superfície das próteses. Os autores recomendam a imersão das peças em $15 \mathrm{~mL}$ de hipoclorito de sódio a $2,25 \%$ diluídos em $200 \mathrm{~mL}$ de água durante 10 minutos a cada 4 dias ${ }^{17}$.

No estudo de Adriana et al, foram testados 4 tipos de agentes químicos (hipoclorito de sódio a $2 \%$, ácido acético a $5 \%$, gluconato de clorexidina a $0,12 \%$ e peróxido alcalino) na higienização de próteses totais e o hipoclorito a $2 \%$, junto à clorexidina a $0,12 \%$, foram as soluções higienizadoras de próteses mais efetivas na inibição do crescimento de Candida albicans ${ }^{32}$.
Falah-Tafti et al, pesquisaram a efetividade de duas substâncias higienizadoras (hipoclorito de sódio a $0,5 \%$ e um produto enzimático) em próteses totais. $O$ hipoclorito de sódio a $0,5 \%$ se mostrou mais eficaz na remoção de bactérias do que o produto enzimático, sendo que o tempo de imersão das próteses foi de 40 minutos $^{36}$.

Em estudo in situ realizado por Lima et al, foram avaliados os efeitos do hipoclorito de sódio a 0,5\% e de um produto enzimático na rugosidade da resina acrílica e no acúmulo de biofilme. Ficou demonstrado que a rugosidade da resina acrílica aumentou com o tratamento de ambas as substâncias, mas a formação de biofilme com o uso hipoclorito de sódio a $0,5 \%$ foi estatisticamente menor do que no grupo controle e no grupo do produto enzimático?.

Os hipocloritos são bastante utilizados devido à sua disponibilidade no mercado e ao baixo custo (22). Entretanto, têm o inconveniente de clarear a resina acrílica e causar corrosão no metal das PPRs de cobalto-cromo ou aço inoxidável, sendo contraindicado seu uso em metal ou, no mínimo, tendo seu uso restrito ${ }^{6,27}$.

\section{Ácidos diluídos}

Outra opção de higienização de próteses removíveis pelo método químico são os ácidos diluídos que consistem em soluções comerciais à base de ácido clorídrico de 3 a 5\%, ácido acético a 5\% (conhecido como vinagre) ou ácido fosfórico a $10 \%$ ou $15 \%$. Devem ser aplicados sobre a prótese com uma escova em curto período, sendo bastante efetivos na remoção de cálculo e manchas. No entanto, são pouco divulgados e indicados, pois são nocivos à pele e olhos, requerem cuidado excessivo para sua utilização, além de causarem corrosão ao metal. Por isso, sua utilização deve ser restrita ao uso pelo profissional ${ }^{22,27}$.

Dos ácidos diluídos, o ácido acético é o mais conhecido e já é muito aplicado em outras áreas como na engenharia de alimentos. Porém, na Odontologia, são raros os estudos que comprovem eficácia e que estabeleçam o uso rotineiro como agente higienizador de eleição. Suas vantagens consistem em ser um produto biodegradável, de baixo custo, alta disponibilidade comercial, não 
oferecer riscos ao seu manipulador, além de ser efetivo frente à Candida albicans ${ }^{37,38}$.

\section{Desinfetantes}

O desinfetante mais conhecido pelos dentistas para uso intrabucal é a clorexidina, logo também é o mais usado ${ }^{22}$. Outros desinfetantes como o etanol, o salicilato (que é menos eficaz que a clorexidina, mas ao menos não mancham às próteses) ${ }^{29}, 0$ álcool isopropílico e a formalina podem ser usados para desinfecção ocasional e para evitar contaminação cruzada no laboratório para o consultório e viceversa. Essas substâncias são pouco usadas no dia a dia por conta do mau odor e gosto ruim, além dos poucos estudos a respeito dos reais efeitos aos tecidos biológicos. Já o clorofórmio não pode ser usado, pois dissolve o acrílico $0^{6,27}$.

A clorexidina reduz o biofilme e promove melhora na mucosa de pacientes com estomatite protética se utilizada diariamente em solução de $0,2 \%$ de 5 a 10 minutos para imersão, além de prevenir a recorrência dessa infecção. No entanto, provoca descoloração do acrílico com o uso prolongado e pode ocorrer reincidência de fungos se seu uso for suspenso. Uma solução para diminuir o efeito colateral da descoloração do acrílico é embeber um chumaço de algodão ou gaze com clorexidina e deixar sobre a base por, no mínimo, 15 minutos ${ }^{6,22,28,33}$.

\section{Enzimas}

Outra medida é a incorporação de enzimas como método químico (papaína, lípase, amilase, tripsina, mutanase, protease e dextranase). Elas estão disponíveis como tabletes solúveis em água para as próteses serem imersas 1 ou 2 vezes ao dia . São efetivas tanto para bactérias como contra os fungos e são os materiais mais indicados para higienizar os materiais resilientes forradores e os condicionadores de tecido, pois agridem menos a superfície do material ${ }^{35}$.

Esses produtos enzimáticos agem na remoção de depósitos pesados do biofilme das próteses e também previnem a formação de um novo biofilme ${ }^{33}$.

Canay et al, avaliaram a eficácia das enzimas (papaína, tripsina e amilase) como método mecânico de higienização de próteses removíveis e na prevenção de estomatite protética por cândida. Os autores recomendaram a imersão das próteses na solução enzimática por 8 horas para sua total ação e concluíram que a papaína teve maior efetividade. Porém, a associação entre as enzimas protease e mutanase se mostrou mais efetiva do que no uso isolado das mesmas, que têm um desempenho ótimo quando misturadas com água em temperaturas entre $35^{\circ}$ e $65^{\circ}$ graus Celsius ${ }^{6,28}$.

\section{DISCUSSÃO}

Embora exista uma variedade de métodos disponíveis no mercado, observa-se que um paciente que passa a ser portador de uma prótese removível continua com os mesmos hábitos precários de higienização da cavidade oral, bem como do seu aparelho protético. A não orientação correta pelo profissional, as dificuldades relacionadas às características das próteses e a idade avançada da maioria dos pacientes podem explicar tal precariedade ${ }^{17,29}$.

O acúmulo de detritos alimentares e de biofilme sobre a superfície das próteses pode resultar em problemas como halitose, cálculo e pigmentações, além de alterações patológicas ${ }^{6}$. Em se tratando de próteses totais, as lesões mais encontradas são a estomatite protética, a hiperplasia gengival e a candidose ${ }^{10,11}$. Para os casos de usuários de prótese parcial removível, os problemas mais comuns são cárie e doença periodontal nos dentes remanescentes ${ }^{11,39}$.

Desse modo, é de fundamental importância que o profissional esteja apto a ensinar as diversas técnicas de higienização das próteses aos pacientes, inclusive no que diz respeito aos produtos de higienização disponíveis, de forma que sejam oferecidas opções compatíveis com as condições socioeconômicas e de saúde geral do paciente ${ }^{40}$.

Silva et al, fizeram uma comparação entre dois levantamentos feitos com questionários nos anos de 1989, com 98 pacientes, e 2004, com 100 
pacientes, sobre os métodos e materiais de higiene utilizados por usuários de próteses totais. Constatouse que houve um aumento do número de pacientes que receberam informações dos profissionais quanto à forma de higienização já que no ano de 1989, 81 pacientes $(82,6 \%)$ não receberam nenhuma orientação e em 2004 esse número foi de 52 pacientes (52\%). Entretanto, quanto à orientação de visitas periódicas não houve mudança significativa quando aproximadamente $80 \%$ dos entrevistados não recebeu tal orientação ${ }^{15}$. Isso evidencia que houve uma melhora da atitude dos profissionais, mas que ainda precisa ser mais difundida a orientação quanto à higienização e reconsultas. Nesse contexto, o retorno periódico é fundamental, pois permite o diagnóstico precoce, o controle e a prevenção da cárie e doença periodontal ${ }^{41}$.

Em estudo de Cruz et al, foram pesquisados os hábitos de higiene oral de 90 pacientes portadores de prótese total e observou-se que $75 \%$ dos pacientes não receberam instrução do cirurgiãodentista quanto à higiene dos tecidos moles e apenas $24 \%$ receberam instrução quanto a higiene das peças protéticas ${ }^{7}$.

Baran \& Naçalci, em 2009, examinaram 310 próteses totais de idosos entre 60 e 85 anos e, através de um questionário, constataram que a grande maioria $(93,6 \%)$ dos pacientes alegaram higienizar suas próteses com escova de dente comum (com uso da pasta de dente ou não) e menos de $10 \%$ alegaram higienizar suas próteses com alguma substância química. Nesse estudo, foi observada uma relação positiva entre a má higiene das próteses e a presença de estomatites e úlceras na mucosa. Os autores consideraram a higiene das próteses, boa em 57 participantes (18,4\%), satisfatória em 121 (39\%) e pobre/ruim em 133 participantes (42,9\%). Por fim os autores concluíram que os pacientes não recebiam informação suficiente sobre os cuidados com suas próteses ${ }^{12}$.

Lima et al, avaliaram o conhecimento sobre métodos de higienização de 100 pacientes usuários de próteses removíveis através de um questionário. Nesse estudo, todos os pacientes relataram utilizar a escova com dentifrício para limpeza das peças, sendo que $97 \%$ usavam escova dental comum, e apenas $32 \%$ dos pacientes receberam instruções dos dentistas sobre higienização das próteses?
Em estudo de Dikbas et al, 325 dentistas responderam um questionário que avaliava se eles propunham aos seus pacientes algum método de higienização das suas próteses totais e qual método indicava. Apenas $6,1 \%$ dos entrevistados afirmaram que não indicavam nenhum tipo de método para higiene das próteses e $78,2 \%$ propuseram a imersão das peças em algum tipo de substância química associado à sua escovação como método ideal de higienização 42.

Em estudo de Sesma et al, 10 pacientes foram submetidos à higienização de próteses totais por dois métodos: escovação com dentifrício e associação de escovação com dentifrício e imersão da prótese em produto químico enzimático. Em análise microbiológica, foi observado redução da contagem de microorganismos com o tratamento químico/mecânico em relação ao método mecânico isolado ${ }^{30}$.

O que se observa na literatura é uma dificuldade na padronização nos estudos que comparam entre si os diversos métodos de higienização de próteses removíveis disponíveis. Muitos estudos revelam maior eficácia de um ou de outro método, porém não existe uniformidade entre as concentrações das substâncias químicas utilizadas, nem nos tempos de imersão, nem no mecanismo de se realizar os procedimentos mecânicos. Isso torna difícil a determinação da melhor maneira de higienização das próteses. $O$ que se sabe é que o método mecânico e químico de higienização, quando empregados isoladamente, não removem de maneira adequada as bactérias e fungos da superfície das próteses $17,18,22,30,35,38,42$.

Desta forma, a maneira mais eficaz de higienização das próteses removíveis é a associação entre os dois métodos. É a conduta de eleição, pois o método mecânico remove os indutos presentes e os agentes químicos agem diretamente nos componentes do biofilme, sendo eficazes contra os microrganismos presentes, na prevenção da halitose e da estomatite protética $^{14,35}$. Porém, deve-se sempre levar em conta as condições socioeconômicas e de saúde geral do paciente ${ }^{43}$, o tipo de prótese e o material que aquela prótese possui para que $\circ$ profissional consiga associar e indicar os melhores métodos de higienização das peças removíveis dos pacientes. 


\section{CONSIDERAÇÕES FINAIS}

Na reabilitação bucal, é de responsabilidade do profissional conhecer os materiais e métodos empregados no controle do biofilme das próteses removíveis, selecioná-los e, de acordo com as peculiaridades de cada caso e das condições de saúde geral e socioeconômicas do paciente, motivar e orientar sua aplicação, para que o paciente possa conservar o estado de saúde obtido com o tratamento.

Apesar de haver uma variedade de métodos de higienização disponíveis para limpeza das próteses removíveis, parece ser consenso na literatura que, a maneira mais eficaz é a associação dos métodos mecânico e químico, sendo recomendado a escovação diária aliada à imersão das peças em uma substância química, de acordo com o tipo de prótese do paciente.

\section{REFERÊNCIAS}

1. Ribeiro DG, Pavarina AC, Dovigo LN, Spolidorio DMP, Giampaolo ET, Vergani CE. Denture disinfection by microwave irradiation: a randomized clinical study. J Dent. 2009;37:666672. doi: 10.1016/i.jdent.2009.04.009

2. Glass RT, Conrad RS, Bullard JW, Goodson LB, Mehta N, Lech SJ et al. Evaluation of microbial flora found in previously worn prostheses from the Northeast and Southwest regions of the United States. J Prosthest Dent. 2010;103(6):384-389. doi: 10.1016/S0022-3913(10)60083-2

3. Sheen SR, Harrison A. Assessment of plaque prevention on dentures using an experimental cleanser. J Prosthet Dent. 2000;84(6):594-601. doi: $10.1067 / \mathrm{mpr} .2000 .110498$

\section{Abelson DC. Denture plaque and denture} cleansers. J Prosthet Dent. 1981;45(4):376-9.

5. Nikawa H, Hamada T, Yamamoto T. Denture plaque--past and recent concerns. J Dent.
1998;26(4):299-304. doi: 10.1016/50300$5712(97) 00026-2$

6. Silva RJ, Seixas ZA. Materiais e métodos de higienização para próteses removíveis. Int J Dent. $2008 ; 7(2): 125-32$.

7. Cruz PC, Pardini LC, Paranhos HFO. Hábitos de higienização de portadores de prótese total; escovação de tecido mole: um levantamento. Rev Odont UNAERP. 1999;3(1).

8. Silva CHL, Paranhos HFO, Ito IY. Evidenciadores de biofilme em prótese total: avaliação clínica e antimicrobiana. Pesqui. Odont. Bras. 2002;16(3):270-5. doi: 10.1590/S151774912002000300015

9. Lima EMCX, Moura JS, Garcia RCMR, Cury AADB. Avaliação dos materiais e métodos de higiene utilizados por pacientes usuários de próteses removíveis em atendimento na clínica FOP-UNICAMP. Rev. Odonto Ciência. 2004;19(43):90-95.

10. Goiato, MC, Castelleoni L, Santos DM, Gennari Filho $\mathrm{H}$, Assunção WG. Lesões orais provocadas pelo uso de próteses removíveis. Pesq. Bras. Odontoped. Clin. Intgr. 2005;5(1):85-90.

\section{Almeida Júnior $A A$, Neves $A C C$, Araújo, $C C N$,} Ribeiro CF, Oliveira JLG, Rode SM. Avaliação de hábitos de higiene bucal em portadores de próteses removíveis da Faculdade de Odontologia da Universidade Federal de Sergipe. Comun Ciênc Saúde. 2006;17(4):283-289.

\section{Baran I, Nalçaci R. Self-reported denture} hygiene habits and oral tissue conditions of complete denture wearers. Arch of Geront and Geriat. 2009;49:237-241. doi: 10.1016/i. archger.2008.08.010

\section{Montagner $\mathrm{H}$, Montagner F, Braun KO, Peres} PE, Gomes BP. In vitro antifungal action of different substances over microwaved-cured acrylic resins. J Appl Oral Sci. 2009;17(5):432-435. doi: 10.1590/ S1678-77572009000500015

14. Souza RF, Paranhos HFO, Silva CHL, AbuNaba'a L, Fedorowicz Z, Gurgan CA. Interventions for cleaning dentures in adults. Cochrane Database 
of Systematic Reviews. 2009;4: CD007395. doi: 10.1002/14651858.CD007395.pub2

\section{Angst PDM, Gomes SC, Oppermann RV.}

Do controle de placa ao controle do biofilme supragengival: o que aprendemos ao longo dos anos?. Rev. Assoc. Paul. Cir. Dent. 2015;69(3):252259.

16. Reeson MG. A modified denture cleaning brush for patients with limited manual dexterity. J Prostht Dent. 2003;90(2):205-6. doi: 10.1016/ S002239130300369X

17. Catão CDS, Ramos INC, Silva Neto JM, Duarte SMO, Batista AUD, Dias AHM. Eficiência de substâncias químicas na remoção do biofilme em próteses totais. Rev Odont UNESP. 2007;36(1):5360.

\section{Liaño GP, Ezpeleta AO. Hábitos en el} mantenimiento e higiene de las prótesis removibles: estudio comparativo entre dos sistemas de limpieza. Gaceta Dental: Industria y Profesiones. 2008;(192):162-169

19. Paranhos HFO, Panzeri H, Lara EHG, Candido RC, Ito IY. Capacity of denture plaque/biofilm removal and antimicrobial action of a new denture paste. Braz Dent J. 2000; 1 1 (2):97-104

\section{Neppelenbroek KH. Efetividade da} desinfecção de próteses totais por energia de microondas no tratamento de estomatite protética [PhD thesis]. Araraquara: Universidade Estadual Paulista, Faculdade de Odontologia; 2005.

\section{Jorge JH, Giampolo ET, Vergani CE,} Machado AL, Pavarina AC, Rodrigues MG. Efeito da desinfecção em microondas sobre a microinfiltração na interface de resinas para base e reembasamento de prótese. Rev de Odont da UNESP. 2007;36(3):261-266.

\section{Kazuo SD, Ferreira UCS, Justo KD, Rye OE,}

Shigueyuki EU. Higienização em prótese parcial removível. Odont Univ Cidade de São Paulo. 2008;20(2):168-4.

23. Silva MM. Efetividade da irradiação por microondas na desinfecção de próteses totais.
Universidade de São Paulo. Araraquara; 2005.

24. Sartori EA, Schmidt CB, Walber LF, Shinkai RSA. Effect of Microwave Disinfection on Denture Base Adaptation and Resin Surface Roughness. Braz Dent J. 2006;17(3):195-200. doi: 10.1590/S010364402006000300004

25. Hussen AM, Rejab LT, Abbood LN. The Effect of Microwave Disinfection on the Dimensional Change of Acrylic Resins. Al-Rafidain Dent J. 2008;8(1):3843.

26. Santos PH, Gomes EA, Pavan S, Vergani CE. Energia por microondas: efeito na estabilidade dimensional de resinas acrílicas. Rev de Odont da Unir Cid de São Paulo. 2007;19(1):84-9.

27. Budtz-Jorgensen E. Materials and methods for cleaning dentures. J Prosthet Dent.

1979;42(6):619-23.

28. Nunes JMC, Oliveira LV, Lira AF, Mesquita MF, Henriques GEP, Consani RLX. Efeito de agentes químicos de limpeza de próteses sobre as características superficiais de materiais reembasadores resilientes. Cienc Odontol Bras. $2008 ; 11(2): 71-7$.

29. Cruz PC. Avaliação clínica da efetividade dos métodos químico (peróxido alcalino) e mecânico (ultra-som) frente à propriedade de remoção de biofilme de próteses totais [Dissertação]. Ribeirão Preto: Universidade São Paulo; 2007.

30. Sesma N, Laganá DC, Gil C, Morimoto S. Capacidade de remoção do biofilme por meio de um produto enzimático para higienização de bases protéticas. Rev Pós Grad 2005;1 2(4):417-22.

31. Martins da Silva EM, Silva Filho $C E$, Nepomuceno VC. Uma grande descoberta: - prazer que a higienização bucal correta e bem orientada pode proporcionar. Rev Odont Araçatuba. 2003;24(2):39-42.

\section{Adriana UB, Gladys RM, Antonio BL. Acción} de agentes químicos en la eliminación de cándida albicans sobre prótesis dentales. Acta Odont Ven. 2007;45(2). 
33. Canay S, Ergüven S, Yulug N. The function of enzymes in removing candida accumulated on denture plaque. J of Islamic Academy of Sciences. $1991 ; 4(1): 87-89$.

\section{Uludamar A, Özkan YK, Kadir T, Ceyhan} I. In vivo efficacy of alkaline peroxide tablets and mouthwashes on Candida albicans in patients with denture stomatitis. J. Appl Oral Sci. $2010 ; 18(3): 291-6$.

\section{Murata $H$, Chimori $H$, Hong $G$, Hamada $T$,} Nikawa H. Compatibility of tissue conditioners and denture cleansers: Influence on surface conditions. Dent Mater J. 2010;29(4):446-453. doi: $10.4012 /$ dmj.2009-135

36. Falah-Tafti A, Jafari AA, Lotfi-Kamran $M H$. Comparison of the Effectiveness of Sodium Hypochlorite and Dentamize Tablet for Denture Disinfection. World Journal of Medical Sciences. 2008;3(1):10-14.

37. Azuma CRS, Cassanho ACA, Silva FC, lto CYK, Jorge AOC. Atividade antimicrobiana de soluções de ácido acético de diferentes tipos e procedências sobre Candida albicans. RPG rev. 2006;13(2):164-167.

38. Pinto TMS, Neves ACC, Leão MVP, Jorge AOC. Vinegar as an antimicrobial agent for control of Candida spp. in complete denture wearers. J. Appl. Oral Sci. 2008;16(6):385-390. doi: 10.1590/ S1678-77572008000600006

39. Silva P.M.B; Porto, V.C. Bonachella, W.C. Aspectos periodontais em pacientes usuários de prótese parcial removível. Rev. Odonto Ciênc. 2008;23(2):297-301.

40. Mezzomo E. Reabilitação oral para o clinico. 3 ed. Porto Alegre: Ed Santos; 1997.

41. Pavarina AC, Garcia PPNS, Bonan RF, Giampaolo ET, Vergani CE, Machado AL. Survey the policy adopted by dentists concerning the periodic recalls of patients wearing removable partial. Rev. Odontol. UNESP. 2003;32(1):47-54.

42. Dikbas I, Koksal T, Bal B, Ozkurt Z, Kazaoglu E. A survey of dentists' attitudes toward denture cleansing. OHDMBSC. 2006;5(4):7-11.

43. Dias JN, Silva MPCF, Lima IPC. The use of aroreira-based phytotherapics as a supporting tool in the treatment of gingivits: $A$ systematic Review. Revista Brasileira de Plantas Medicinais. 2015;17(4-Suppl3):1 187-1 191. doi: 10.1590/1983-084X/14_164 